\title{
GOVERNMENT-CIVIC GROUP CONFLICTS AND COMMUNICATION STRATEGY: A TEXT ANALYSIS OF TV DEBATES ON KOREA'S IMPORT OF U.S. BEEF*
}

\author{
Seong Eun Cho ${ }^{*}$, Myunggoon Choi and Han Woo Park ${ }^{+}$
}

This study analyzes messages from Korean TV debates on the conflict over U.S. beef imports and the process of negotiations over the imports in 2008. The authors have conducted a content analysis and a semantic network analysis by using KrKwic and CONCOR. The data was drawn from nine TV debates aired by three major TV networks in Korea (MBC, KBS, and SBS) from 27 April 272008 to 6 July 2008. The results indicate substantial differences in the semantic structure between arguments by the government and those by civic groups. We also investigated the relationship between the terms frequently used by both sides (i.e., the government and civic groups), and the terms used exclusively by one side. There was a gradual increase in the number of terms frequently used by both sides over time, from the formation of the conflict to its escalation to its resolution. The results indicate the possibility of general agreement in conflict situations.

\section{Keywords}

Conflict, Civic Group, Government, Semantic Network, TV Debate, U.S. Beef Import

Korea's candlelight vigil against the import of U.S. beef in 2008 can be viewed as a new social conflict arising from a failure to adequately adopt new communication strategies based on advanced digital technologies in the information age. The government and domestic stakeholders are often at odds over issues related to international trade in the global era. In other words, when administering state affairs or engaging in general business, people are increasingly likely to encounter situations similar to that involving government-civic group conflicts over U.S. beef imports in 2008. Therefore, it is necessary to understand and analyze the process by which the 2008 candlelight vigil formed public opinion and continued to encourage the general public to participate in the rallies, and the reason why the Korean government failed to implement and promote appropriate policies to adequately address the widespread fear of mad cow disease. Although the candlelight vigil was not able to resolve the conflict, it provides a typical example of conflicts between the public and private sectors

\footnotetext{
* An earlier version of this paper was published (in Korean) as a chapter in 공정사회와 갈등관리 (Fair Society and Conflict Management)

* Seong Eun Cho, Cyber Emotions Research Center, Yeungnam University, South Korea

- Myunggoon Choi, Cyber Emotions Research Center, Yeungnam University, South Korea

${ }^{+}$Han Woo Park, Corresponding Author, Department of Media and Communication, YeungNam University, South Korea
} 
over social issues in recent years. Therefore, it is necessary to fully understand and analyze the mechanism of such conflicts.

The protest against the import of U.S. beef provides an important opportunity for understanding how members of society express and share their own understanding and demand through the media, and how their individual opinions are reflected in social conflicts. Further, this case is significant in showing how it can provide a better understanding of the process by which a conflict requiring diverse communication methods is resolved through the media.

The Korean government used a PR strategy for its policies, relying on conventional media methods, such as TV debates without adequately considering various changes in the media environment, such as the convergence of old and new media. This strategy limited the communication between the government and the public, and intensified the government-civic group conflict. In this regard, by focusing on changes in the media environment, an analysis of the communication process during the candlelight vigil should have important implications for policymakers interested in establishing effective strategies for resolving similar conflicts in the future.

\section{Introduction to the Conflict}

In December 2003, the U.S. Department of Agriculture confirmed the first case of mad cow disease. In response, the Korean government banned the import of U.S. beef. Although the U.S. government continued to call on the Korean government to resume imports, the Korean government refused. In 2006, however, the Korean government agreed to resume the import of U.S. beef under the condition that it would allow the import of 'only beef muscle meats without bone from cow that is less than 30 months old.' As the negotiations continued, the Humane Society of the United States (HSUS), a major animal rights group in the U.S., posted a video on YouTube (a video-sharing site) in February 2008. The video, which went viral, showed abused cows dying in some slaughterhouses.

In April of the same year, the controversy over mad cow disease intensified as the second round of negotiations over U.S. beef imports between Korea and the U.S. was announced to be concluded one day before the Korea-US summit. In the meantime, MBC, a TV network in Korea, aired its regular program PD Notebook on 29 April under the title 'Emergency overage! Is U.S. beef really safe from mad cow disease?' The program pointed out various problems associated with the negotiations, and raised the possibility of U.S. beef being infected with mad cow disease. The general public thus started paying increasing attention to the issue, turning it into a nationwide social issue. Afterward, news reports continued covering the controversy, and in-depth debates followed.

On 2 May 2008, the first candlelight vigil was held at the Cheonggye Plaza in Jongno District (Seoul, Korea). The vigil attracted approximately 20,000 people who were against the resumption of U.S. beef imports. Since the first candlelight vigil, many rallies were held in various places, mostly in Seoul. The Internet was also used for the protest. Whenever the media released news stories about the risk of mad cow disease and problems with the negotiations, a large number of internet users paid close attention to them and exchanged their opinions through various internet channels, such as Agora, a popular online discussion board by Daum Communications. People protesting against U.S. beef imports on this medium launched a signature campaign for the impeachment of President Myung-bak Lee, drawing more than one million participants as of 6 May $2008^{1}$. After the largest rally on June 10, the government finally engaged in an additional round of negotiations with the U.S., and later, it published a notification to the public through the official gazette. 


\section{TV Debates}

After 18 April 2008, when the conclusion of the negotiations was announced to the public, conflicts between the government and civic groups started to emerge. At the same time, the major TV networks in Korea (KBS, MBC, and SBS) hosted a number of TV debates on the main disputes between the government and civic groups. For example, after announcing the conclusion of negotiations over U.S. beef imports on 18 April, KBS hosted Midnight Debate on 27 April. When KBS hosted Inside the Issues on May 4, Civic groups started a 'onemillion-Internet-user signature-seeking campaign for the impeachment of President Myungbak Lee.' TV debates thus were involved with major issues relating to political actions.

\section{Major Stakeholders and Types of Conflicts}

The conflicts that emerged from the protest against U.S. beef imports can be classified into conflicts of value and conflicts of interest. First, conflicts of value refer to conflicts between the digital nomad generation and the analog generation. The digital nomad generation refers to people who use diverse digital media and those who engage in brisk interactions with others who have a wide range of social backgrounds. Consequently, this generation enjoys horizontal social interactions with diluted traditional social hierarchies.

In contrast, the analog generation tends to depend on conventional media and be familiar with one-way or top-down communication methods, which are associated with the technological characteristic of conventional media (e.g., television, print media, and radio). The government's PR efforts to disseminate information on the safety of U.S. beef were focused mainly on unilateral and vertical analog media. However, this way of communication clashed with that preferred by the new digital nomad generation, intensifying the misunderstanding and conflicts between the government and the public.

Second, conflicts of interest involve conflicts between the government's political and diplomatic approach and the public's expectation of social welfare promotion. Although people recognized the position of the government that domestic and foreign affairs needed to be taken into consideration and that Korea could not disregard potential diplomatic tension, they tended to show negative attitudes toward the government's position because they were very concerned that the government would pursue diplomacy at the expense of their health and welfare. These negative attitudes, which were directed mainly at the ruling party and the government, can be attributed to the widespread public distrust of the Lee administration and its inner political circle, which typically increases after a new president is sworn in. Even worse, the Grand National Party, the ruling party, which vehemently opposed U.S. beef imports during the Moo-hyun Roh administration, the previous administration, started to strongly support the imports without providing any clear reason. This turnaround had a substantial negative impact on the government's effort to influence the general public.

Further, this turnaround was viewed by people as a turf war between political rivals, resulting in the belief that politicians were engaging in this conflict at the expense of the health of the public. Thus, even those people who might have understood the government's position started opposing the government's plans and became tougher critics of the government's position. To a certain extent, these changes in attitudes may be attributed to the inconsistent attitudes of the political circle. Consequently, the protest against U.S. beef imports escalated into the political demand for the resignation of President Myung-bak Lee. Based on the process by which they intensified, the conflicts indicated by the protest against U.S. beef imports appear to reflect spillover conflict, which is a type of conflicts that a certain issue goes beyond the initially set scope and rapidly spreads to other directions. 


\section{Method}

\section{Data Collection and Analysis Techniques}

We conducted content analyses of points in dispute, including those related to the way that the protest developed, the communication process during the protest, and conflicts of interest among stakeholders, to analyze the conflicts associated with the protest against U.S. beef imports. Content analysis allows for an examination of the meaning or key idea of messages. ${ }^{2}$ In this study, we used KrKwic, a Korean text analysis software package, to extract the cooccurrence matrix of frequently used terms. KrKwic is useful for examining not only the frequency of the occurrence of particular terms, but also the combination of specific words and the degree of the combination. ${ }^{3}$

We also analyzed the points in dispute by conducting a semantic network analysis, a type of social network analysis, in which the term is the basic unit of analysis. ${ }^{456}$ Social network analysis explains the units and their relationship expressed in the social network (structure), and can be useful for analyzing conflicts. ${ }^{7}$ A social network consists of dots (nodes), which indicate the unit of analysis (e.g., individuals, groups, or words), and lines, which display the relationship among units of analysis. The matrices that form a social network include one-mode matrices and two-mode matrices. One-mode matrices display various characteristics that are based on the direct interrelationship among nodes, whereas two-mode matrices show mutual similarities inferred from the indirect interrelationship among nodes.

For the semantic network analysis, we conducted a CONCOR (CONvergence of iterated CORrelations) analysis by using UCINET, a tool for social network analysis ${ }^{8}$. Employing CONCOR, we classified the messages by the two sides into several categories and analyzed the text. We also articulated the semantic structure revealed in the 'word' $\times$ 'word' cooccurrence matrix by using KrKwic, and determined the relationship between hidden subgroups in each group. We visualized these network results by using NetDraw ${ }^{9}$.

Although a network's density is useful for determining the degree of the relationship between nodes in the network, it is influenced by the number of nodes because it uses the concept of average. That is, if the number of nodes increases, the density of the network tends to decrease. In terms of the network analysis of individual debaters in this study, the numbers of debaters in each group differed. Accordingly, we used network centrality, rather than the density of the network, to explore the differences in the conflict structure between the groups to which individual debaters belonged.

Network centrality is a value representing the location of each node in the network and is subdivided into four types: degree, closeness, relations between them, or eigenvector centrality. Degree centrality refers to the degree of being concentrated in a specific node and is the sum of other nodes connected directly to a node. Degree centrality is used to measure the centrality of a specific node. Closeness centrality refers to the distance between two nodes within the network, and betweenness centrality represents those nodes playing a role as a broker. Eigenvector centrality (symmetric without directionality) is a value representing the importance of a node in the network, and is based on the principle that nodes showing higher centrality are given a higher score. That is, a node showing higher eigenvector centrality is more influential than that showing lower eigenvector centrality in the network. Based on these concepts, we analyzed a network of groups to which individual debaters belonged. 


\section{Research Object}

We analyzed the content of TV debates on U.S. beef imports and the process of negotiations over the imports. TV debates are useful for identifying differences in the ideological stance between pro-government and opposition groups ${ }^{1011}{ }^{13}$. Accordingly, we expect that the content analysis of TV debates would articulate some important differences in the semantic structure between arguments by the government and those by civic groups. In addition, we analyzed the relationship between the terms frequently used by both sides, i.e., the government and civic groups, and the terms used exclusively by each side to determine whether general agreement is possible in conflict situations.

The data for the content analysis were drawn from debate programs by three major TV networks in Korea (MBC, KBS, and SBS) from 27 April 272008 to 6 July 6 2008. These networks hosted a total of 19 debates during this period. However, we used messages from only nine debates, which were selected based on the following two criteria: the first criterion was whether the debate was exposed to mass media (e.g., newspapers or broadcast networks). We used Naver (www.naver.com) for this, which is a major portal as well as a search engine in Korea. Employing their 'news title search' service, we extracted keywords referring to various TV debate programs (e.g., '100 Minute Debate,' 'Current Affairs Debate,' 'Midnight Debate,' and 'Inside the Issues'), and searched for relevant news using the keywords between 1 April 1 2008, and 30 July 30 2008. If a certain debate program had one or more news stories mentioning the program, then it was considered more important than the one with no news coverage. The second criterion was whether the debate topic was directly related to U.S. beef imports. For example, a debate program using the case of U.S. beef imports to address the topic of the Korea-U.S. FTA and other state affairs was considered less important than the one directly covering the topic of U.S. beef imports. Further, we divided the debaters into those from the government and those from civic groups. Those debaters who were neutral in their opinions, mostly those from academia, were excluded from the final analysis.

\section{Frame Approach}

This study adopted frame theory to analyze the positions of stakeholders with respect to their opposition to U.S. beef imports. Framing helps stakeholders to understand their own situation and form judgments about various incidents. Given that conflicts result from gaps between individuals' frames, frame analysis can highlight differences between conflicting frames. ${ }^{14}$. Frame analysis allows for an examination of how stakeholders manage conflicts and choose solutions. There can be controversies when stakeholders in conflict show different preferences for managing and resolving a conflict. For the management of such conflicts, Lewicki et al $^{14}$ proposed nine types of frames: a) avoidance-obedience, which refers to no action to resolve problems; b) fact finding, which refers to the collection of more scientific information to resolve problems; c) solving public problems, which refers to individuals' participation in the decision-making process to reach general agreement or the government's evaluation of stakeholders' opinions before making a decision directly; d) decision by the authorities, which refers to decisions by a local assembly, a government organization, or a government agency; e) judgment, which refers to decisions by a third party, the court, or judicial authorities; f) appeal for political action, which refers to problems resolved by controlling, establishing, or abolishing laws; g) appeal for a market economy, which refers to conflicts dealt through market solutions, or negotiations for changes in the economic system; h) violence, which refers to the threat of force; and, i) other, which refers to decisions made on the basis of 'common sense' that does not deviate from justice. 


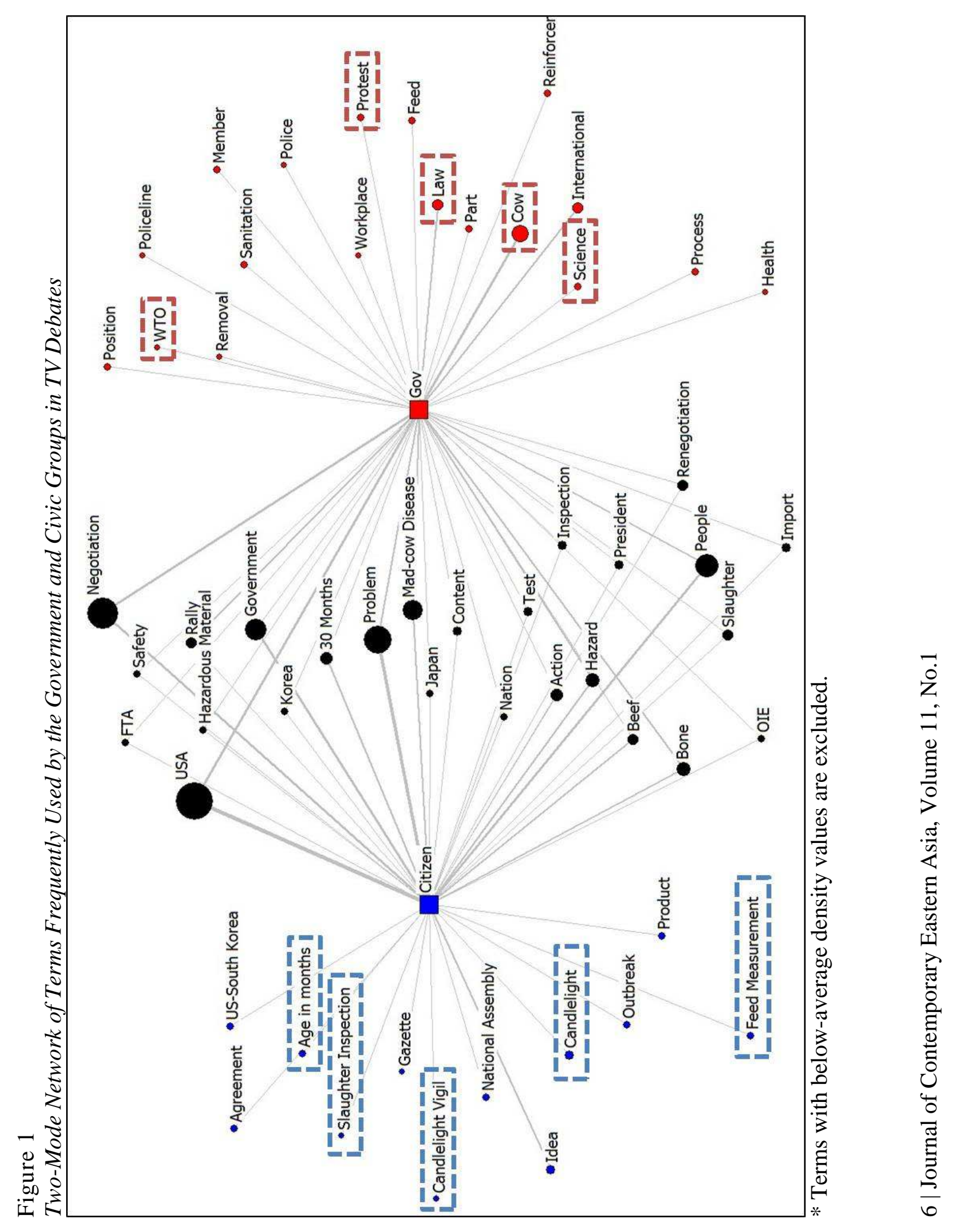




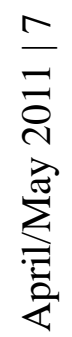

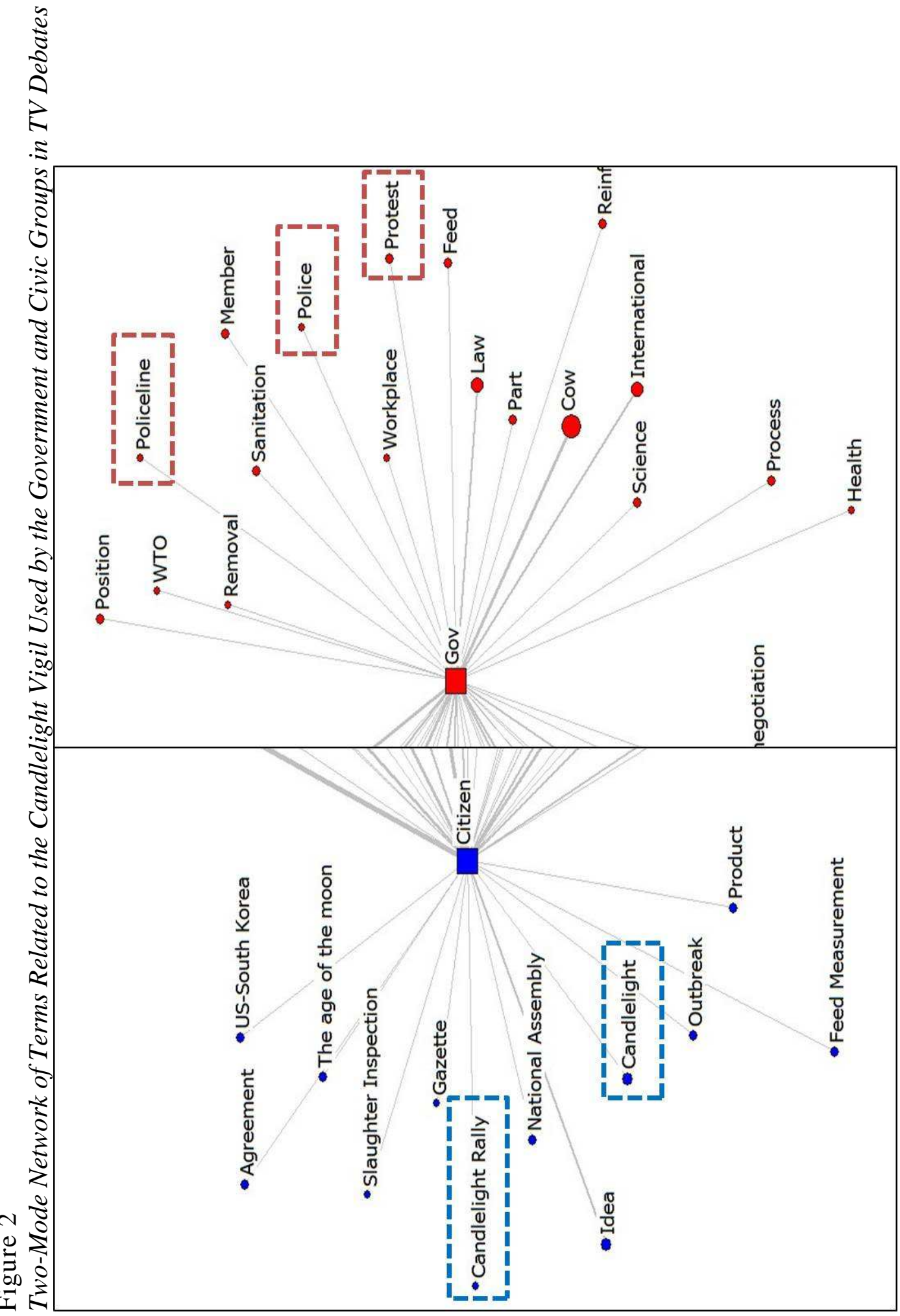




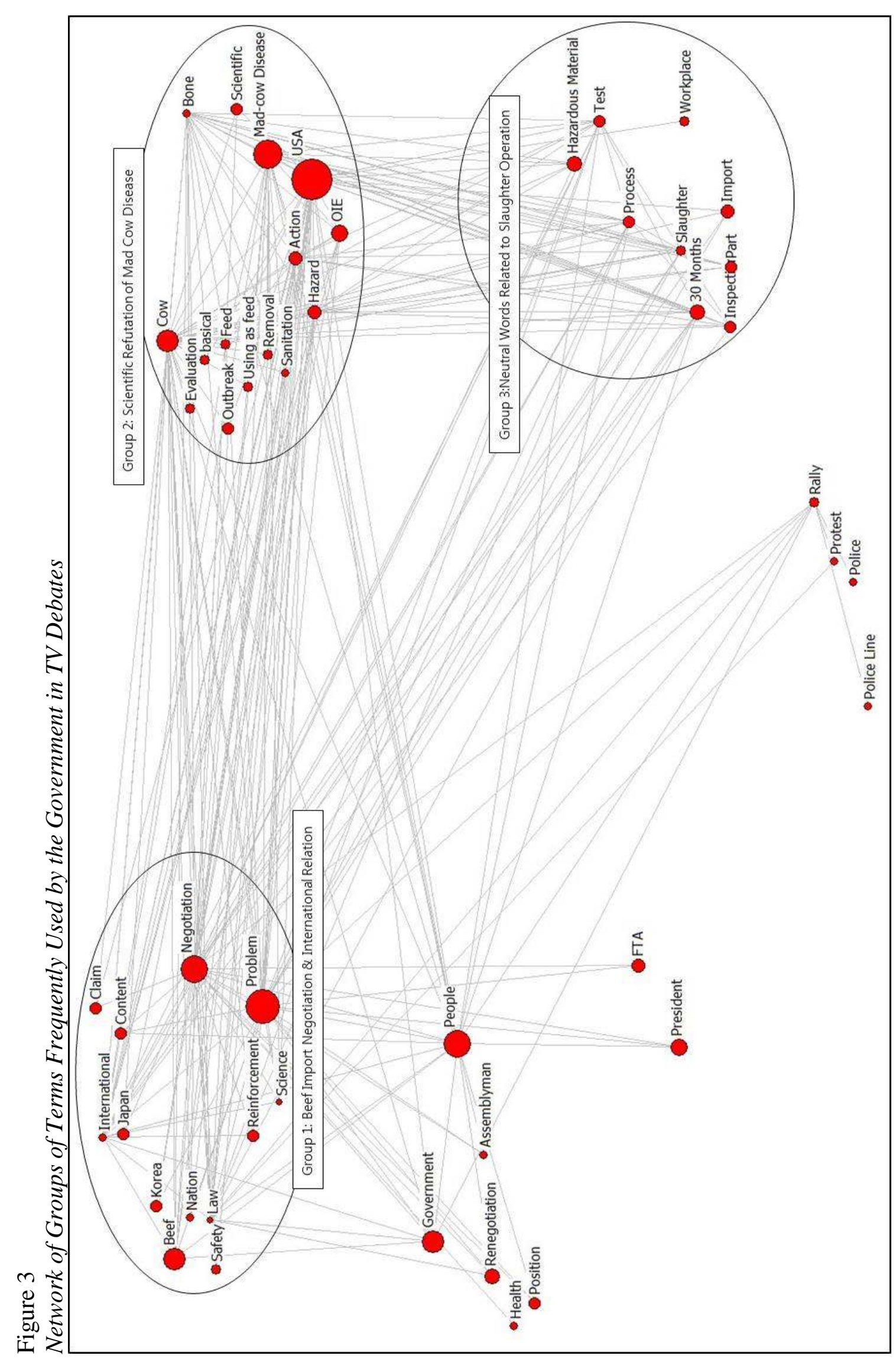

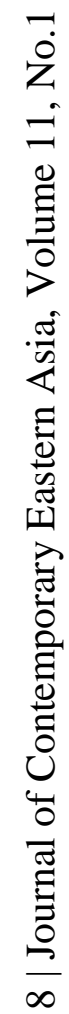




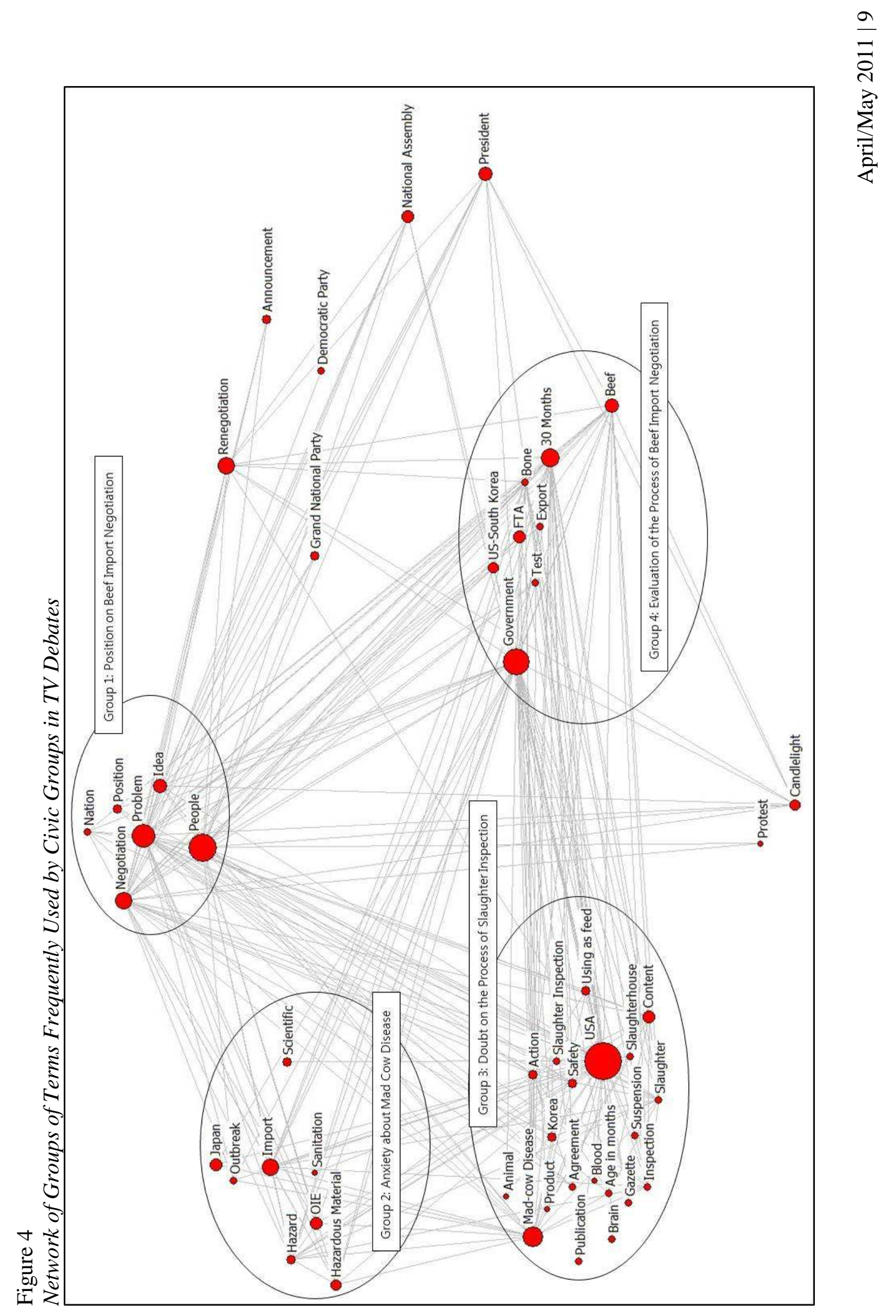




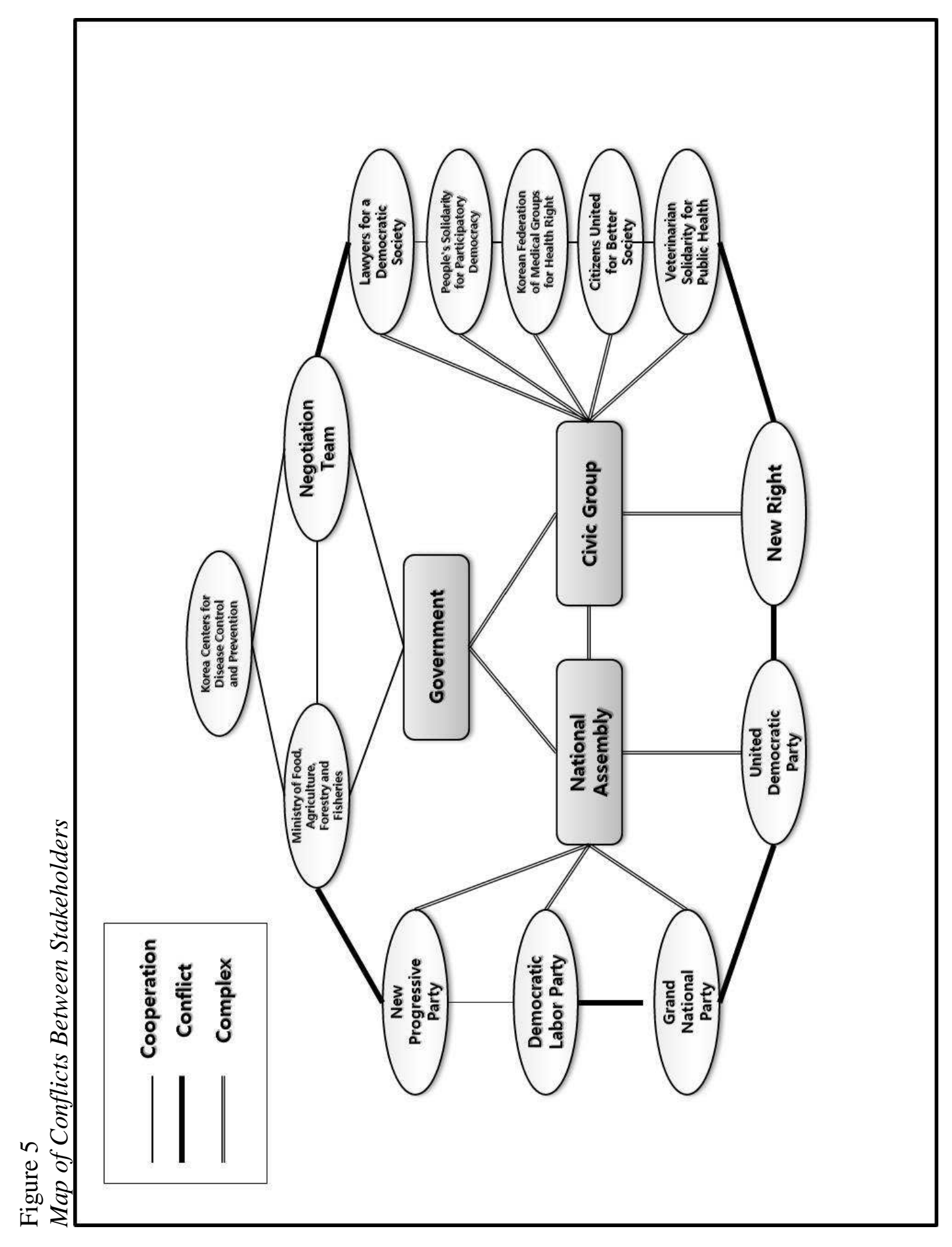

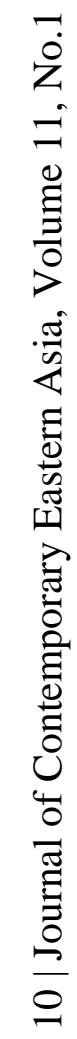


Figure 6

Map of the Network of Stakeholders Based on Degree Centrality

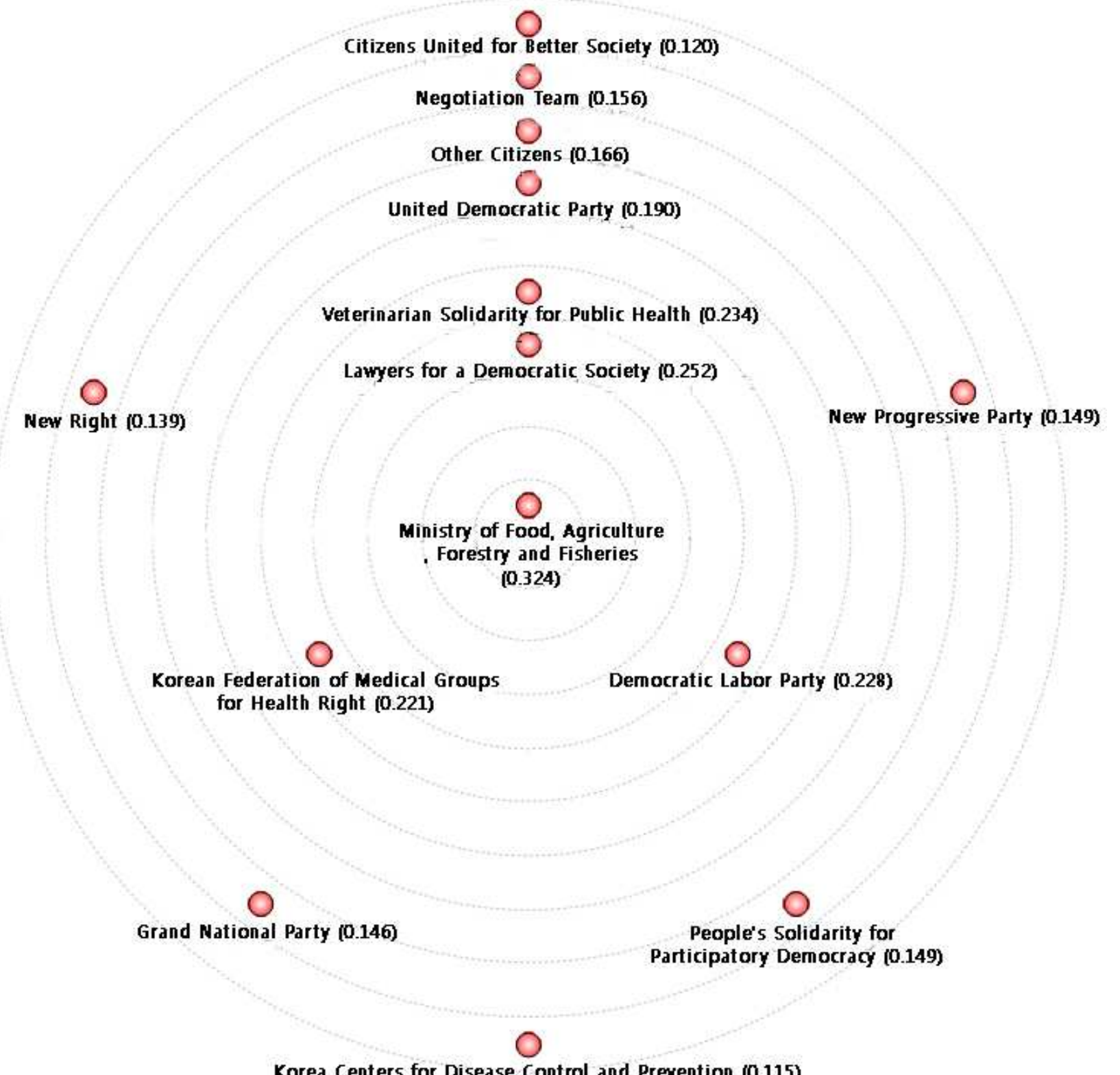

Korea Centers for Disease Control and Prevention (0.115) 


\section{Results and Discussion}

\section{Network of Terms Used in TV Debates}

Figure 1 shows the network of terms frequently used by the government and civic groups in TV debates. As shown in Figure 1, the size of the concentric circle symbolizes the frequency of the occurrence of each term. The line links each term to each communication subject that used the term. The thickness of the line presents the frequency of the single occurrence, or co-occurrence of the term for either or both of the communication subjects. The frequency indicates the main point of the debate. The co-occurrence matrix of terms was as follows: 296 (appeared terms) $\times 2$ (the number of stakeholders from the government and that from civic groups). According to the results, the terms that both the government side (GOV) and the civic group side (CITIZEN) used included 'government,' 'problem,' 'negotiation,' '30 months,' 'mad cow disease,' 'people,' 'action,' 'hazard,' and 'renegotiation.' In Figure 1, the co-occurred terms are indicated by black circles. The size of the black circle indicates the frequency of each co-occurred term. Among these, those that both sides used frequently were 'negotiation,' 'USA,' 'problem,' 'government,' 'mad cow disease,' and 'people.' The thickness of the lines that link these terms to the communication subjects indicates that civic groups used these terms more frequently than the government (i.e., the lines linking the terms to civic groups are thicker than those linking the terms to the government). Civic groups mentioned the problem associated with U.S. beef imports more frequently to point out the government's incompetence and insisted on the necessity of renegotiation more strongly than the government.

One the other hand, the government was more likely to use terms such as 'cow,' 'position,' 'protest,' 'law,' 'process,' 'international,' 'WTO,' and 'science' (see the terms in red dotted rectangles on the right-hand side of Figure 1). These terms indicate that the government tended to use neutral and general terms to deliver information. By contrast, civic groups were more likely to use terms such as 'candlelight,' 'candlelight vigil,' 'age in months,' 'using as feed,' and 'slaughter inspection' (see the terms in blue dotted rectangles). These terms indicate that civic groups tended to use more specific terms to further their argument.

To examine the position of each side with respect to the candlelight vigil, we extracted terms related to 'candlelight vigil' for both sides. Civic groups used 'candlelight' and 'candlelight vigil,' whereas the government used 'police,' 'police line,' and 'protest' (see Figure 2 for the terms frequently used by each side). This demonstrates the differences in their opinions about the protest against U.S. beef imports. That is, it indicates that the government regarded the rallies as illegal protests instigated by certain groups, not as voluntary gatherings, whereas civic groups considered the rallies as voluntary gatherings for candlelight vigils ${ }^{15}$.

Employing CONCOR, we classified the messages by the two sides into several categories and analyzed the text. Figures 3 and 4 present the semantic structure revealed by the 'word' $x$ 'word' co-occurrence matrix through KrKwic and the relationship between hidden subgroups for each group.

Government side. Figure 3 shows the results for the government side. Messages from the government side were classified into three groups: a) negotiations over U.S. beef imports and international relations; b) the scientific refutation of mad cow disease; and, c) the explanation of the slaughtering process.

Group 1 included terms such as 'beef,' 'negotiation,' 'problem,' 'Japan,' and 'international,' indicating that the government attempted to resolve the problem by linking the con- 
flict over U.S. beef imports to the issue of international negotiations and relations. Group 2 included terms such as 'World Organization for Animal Health' (OIE), 'mad cow disease,' 'cow,' and 'measure,' indicating that authoritative sources of information (e.g., international organizations) and legal arguments were used to dispel the anxiety and fear among citizens over mad cow disease. Group 3 included terms such as 'hazardous substances,' 'quarantine,' and 'slaughter,' indicating that the government made efforts to address the public's concerns over the slaughtering process by using neutral and objective terms for explaining the slaughtering process.

In terms of the relationship among the three groups, we conducted a CONCOR analysis to identify the clusters. Group 1 was strongly related to Group 2 . In other words, the terms in Group 1 were more likely to occur together with those in Group 2 than with those in Group 3, indicating that the government tried to resolve the conflict by attempting to address the public's anxiety over mad cow disease. For this, the government used authoritative sources of information while appealing to the public's sense of patriotism by claiming that the successful negotiation over U.S. beef imports would play a positive role in improving international relations. Group 3 was weakly related to the other groups, indicating that the government used neutral, objective, and authoritative terms to persuade those who were influenced by civic groups, who cast doubt on the slaughter inspection process.

Civic group side. Figure 4 shows the message network for civic groups. The network analysis classified the messages into four groups: a) the position on the negotiations over U.S. beef imports; b) anxiety over mad cow disease; c) doubts about the slaughter inspection process; and, d) the evaluation of the process of negotiations over U.S. beef imports.

Group 1 included terms such as 'negotiation,' 'people,' 'problem,' and 'thought,' which reflect the opinions and position of the public regarding the negotiations over U.S. beef imports. Group 2 included terms such as 'import,' 'international,' 'risk,' and 'hygiene,' indicating the public's anxiety over the possibility of contracting mad cow disease from consuming U.S. beef. Group 3 included terms such as 'slaughter,' 'using as feed,' 'safety,' 'mad cow disease,' and 'suspension,' illustrating the public's distrust of the slaughter inspection process. Group 4 included terms such as 'government,' 'FTA,' '30 months old,' 'beef,' and 'quarantine,' demonstrating that the evaluation of the government was linked not only to the previous administration but also to the FTA negotiations that were underway.

In terms of the relationship among the four groups, Group 1 was strongly related to Group 2, indicating a negative view of the government's handling of negotiations and anxiety over mad cow disease. Group 2 was strongly related to Group 3, demonstrating that people's distrust of the slaughter inspection process sparked their fear of mad cow disease, or that their fear of mad cow disease induced their distrust.

\section{Message Strategies in TV Debates}

The government's message strategy was to emphasize that its information was based on 'authoritative sources.' Some excerpts from the debates include: 'The U.S. has recently inspected around 17,000 head of cattle and confirmed that none had mad cow disease'; 'In the case of the U.S... (ellipsis)... the country scored 2.97 million points from the World Organization for Animal Health (OIE) for the past seven years, even though it was required to score only 30 thousand points'; and 'The OIE took issue only with backbone and the cranial bone... (ellipsis)... The organization does not place any restriction on bones from other parts.' As indicated by these excerpts, the government identified its source before providing any information. 
The terms used mainly by civic groups were typically related to their own evaluative opinions, not to arguments based on authoritative sources, as indicated by the following excerpts: 'teenage students in middle and high schools are... (ellipsis)... teenagers who enjoy eating hamburgers made of such substandard beef...' and '....democracy of the untouchable....(ellipsis)... I believe that this is a shallow, coined word.' This indicates that, unlike the government, civic groups had no obligation to explain and that they were criticizing the government freely on behalf of the general public, which they believed the country should protect.

In general, when there is a controversy, it is more logical and persuasive to develop arguments based on authoritative sources than to depend on subjective opinions. However, this was not the case for the controversy over U.S. beef imports. Despite the use of authoritative sources, the government became the target of intense criticism by civic groups, which claimed to represent the people. Civic groups were in the position to evaluate the efforts by the government, which the people elected and gave mandate to, so that they could appeal to the emotion of the general public and arouse their sympathy more favorably while incapacitating the rational message strategy of the government. Further, instead of relying only on conventional media, civic groups used various web-based channels, whose two-way, interpersonal, and intimate communication tools allowed for a more favorable evaluation of their 'evaluative opinions.' If their evaluative opinions, which reflected more an emotional communication strategy than a rational one, had been delivered through conventional media, their strategy might have backfired.

By contrast, the government took a rational approach based on authoritative sources and relied mainly on conventional media, as it did in the past. The government's failure in communication reflects not its failure to implement a potent message strategy, but its failure to sufficiently understand the new media environment. The people that the government should have focused on were those belonging to the digital nomad generation, those making full use of new media (e.g., social networking sites) to communicate intimately with online strangers. As a result, the government's message strategy, which targeted people relying mainly on conventional media, focused on the wrong target.

Table 1

Centrality Values for Groups (Semantic Network Analysis)

\begin{tabular}{lllll}
\hline & Centrality & & \\
\cline { 2 - 5 } & Degree & Closeness & Betweenness & Eigenvector \\
\hline Formation Period & 0.351 & 0.477 & 0.070 & 0.037 \\
Escalation Period & 0.371 & 0.491 & 0.070 & 0.040 \\
Resolution Period & 0.472 & 0.504 & 0.332 & 0.054 \\
\hline
\end{tabular}

\section{Conflict Structures among Groups}

We examined the individual debaters representing each group and analyzed the differences in the conflict structure between the groups to which they belonged. A network that is evenly spread in all directions indicates the diversification and equalization of opinions, whereas one that is concentrated in a specific node reflects the phenomenon of centralization (Refer to Table 1).

Degree centrality increased from 0.351 to 0.371 to 0.472 ; closeness centrality increased from 0.477 to 0491 to 0.504 ; and eigenvector centrality increased from 0.037 to 0.040 to 0.054 , indicating a general increase in network centrality. This demonstrates that the 
terms used by the debaters became similar over time and that they were finding ways to resolve the conflict. However, the number of nodes and the number of connections between them decreased from the period of conflict formation to the period of conflict resolution. These changes can be attributed mainly to differences in the sample size between the periods.

Betweenness centrality did not change from the period of conflict formation to the period of conflict escalation but rose sharply from the period of conflict escalation to the period of conflict resolution $(0.070 \rightarrow 0.070 \rightarrow 0.332)$. This indicates that the number of terms playing a role as a broker increased and suggests that the government and civic groups engaged in a tug-of-war over various issues from the period of conflict formation to the period of conflict escalation but that they had fewer issues to argue about from the period of conflict escalation to the period of conflict resolution.

\section{Network Structure Based on Network Centrality by Group}

To determine the structural pattern of the conflict between stakeholders based on network centrality, we used blockmodeling to visualize the relationships among groups of stakeholders. Blockmodeling classifies groups based on their structural identity and relationship. In this study, a total of 14 groups (including other civic group category) with which the debaters were associated were identified for the blockmodeling.

As shown in Figure 5, groups at the top are government-related organizations such as the Ministry of Food, Agriculture, Forestry and Fisheries, the Korea Centers for Disease Control and Prevention, and the Negotiation Team. Among civic groups, New Right was the only conservative NGO (see the bottom in Figure 5). The rest of civic groups, including Lawyers for a Democratic Society, People's Solidarity for Participatory Democracy, the Korean Federation of Medical Groups for Health Rights, Citizens United for Better Society, and Veterinarian Solidarity for Public Health (on the right-hand side of Figure 4), formed conflict relationships with New Right, a pro-government organization. In the National Assembly network, the Grand National Party (the ruling party) showed conflict relationships with all opposition parties (the Democratic Labor Party, the United Democratic Party, and the New Progressive Party). In Figure 4, the different types of lines that link the groups indicate the types of relationships (i.e., cooperation, conflict, and complex) among groups.

Figure 6 shows a spatial map of the network obtained using degree centrality. The center indicates the highest level of network centrality. As shown in Figure 6, the Ministry of Food, Agriculture, Forestry and Fisheries (0.324) occupies the exact center. The groups whose average centrality value was 0.185 or higher included the Ministry of Food, Agriculture, Forestry and Fisheries (0.324), Lawyers for a Democratic Society (0.252), Veterinarian Solidarity for Public Health (0.234), the Democratic Labor Party (0.0229), the Korean Federation of Medical Groups for Health Rights (0.221), and the United Democratic Party (0.190), indicating that they showed higher-than-average centrality.

If a group is located in the center of the spatial map and shows high centrality, it represents the opinions of various groups in the network. However, the centrality value for each group was relatively low, indicating that the Ministry of Food, Agriculture, Forestry and Fisheries, although it showed the highest centrality, did not represent the opinions of all the groups. However, it was clearly an influential group representing the government. By contrast, the results indicate that Lawyers for a Democratic Society, one of the groups opposing U.S. beef imports, best represented the opinions of civic groups. However, the groups opposing the imports did not show substantial differences in the centrality value, indicating that several groups were equally likely to represent the position of civic groups. 


\section{Theoretical Frame Approach}

We assessed the types of conflicts revealed during the entire conflict period by using nine categories adopted by Lewicki et al. ${ }^{14}$. Given the candlelight vigil, the government tended to resolve the conflict by relying on a) facts; b) decisions by the authorities; c) appeals for political action; d) appeals for a market economy; and e) the threat of violence. That is, the government attempted to convey to the public that its solution was based on scientific facts and supported by authoritative organizations. In addition, the government attempted to justify U.S. beef imports by relying on political and economic necessities and even tried to justify its use of physical force to control the candlelight vigil. Civic groups tended to rely on a) facts and b) solutions to public problems. The use of violence for resolving conflicts was negatively associated with the position of civic groups. That is, civic groups were agreeable to resolving conflicts through scientific facts but emphasized democratic participation by the public, not decisions by authoritative organizations. Although this frame approach is theoretical, it provides some important implications for resolving conflicts between the government and civic groups.

\section{Conclusions and Implications}

\section{Reasons for Failing to Resolve Differences in the Position between Parties}

The failure to resolve the conflict between the two sides over U.S. beef imports was due in part to the generation gap based on the distrust of the government. Those belonging to the younger generation are accustomed to leading public opinion and seek persuasive authority, a new type of power that replaces hierarchical power formed by the older generation. Hierarchical power is represented by attributes implicit in conventional sources of power, whereas persuasive authority reflects attributes that attract voluntary compliance by making a deep impression. ${ }^{16}$ Major groups protesting against U.S. beef imports preferred persuasive authority to hierarchical power. In other words, they preferred the communication strategy of drawing participation in communication, encouraging the expression of opinions, and persuading one another in a step-by-step manner to that of suppressing free communication, manipulating information, and exercising unilateral influence.

A unilateral communication method through conventional media may be suitable for exercising hierarchical power, but if the target of communication is the digital nomad generation, then the preferred strategy is one based on information communication. The series of events related to U.S. beef imports, which could have been a short-term conflict, turned into an unnecessary long-term conflict. The conflict escalated with the expansion of antigovernment protests because the government failed to identify the key target of communication and was not familiar with the communication channel the target preferred. The results indicate that the government can be characterized by centralization, instruction, and analog, whereas the digital nomad generation, decentralization, communication, and digital.

Noteworthy is that the general public turned their backs on civic groups while holding protests. This is because civic groups were too complacent about their excellent communication skills in the digital era. As mentioned earlier, most of the people who took part in the rallies did so not because of certain political motives, but because of their personal interest in or anxiety over food safety. As civic groups expanded their protest efforts, they become more political. Such changes in the behavior of civic groups can be attributed to their judgment that 
they had good communication with and won the support of the general public through new media.

However, although new media can facilitate two-way communication, they may be used for unilateral communication, just like analog media, if users do not voluntarily participate in mutual communication. This is akin to the situation in which although two individuals can talk, only one dominates the conversation. Similarly, civic groups started to lead and dominate the conversation, even though both they and the public had access to two-way communication tools. Thus, people either relied more on civic groups or turned their backs on civic groups unilaterally, which might have been one of the main reasons why the conflict eventually subsided. In other words, it is likely that the candlelight vigil lost its momentum not because the government succeeded in communicating with protesters, but because protesters started to have problems communicating with one another. ${ }^{17}$

Table 2

Guideline for Resolving Conflicts by Conflict Stage

\begin{tabular}{lll}
\hline Stage & Government & Citizen \\
\hline Initial Stage & $\begin{array}{l}\text { - Raise awareness of the necessity of sharing in- } \\
\text { formation } \\
\text { - Discard the principle of minimum communica- } \\
\text { tion }\end{array}$ & $\begin{array}{l}\text { - Consider the possibility of de- } \\
\text { laying the public distribution of } \\
\text { information } \\
\text { - Discard the principle of the } \\
\text { maximum information benefit }\end{array}$ \\
\end{tabular}

- Cultivate media literacy, which - Create an internet environment for smooth com- enables informed judgments on Intermediate munication with stakeholders

Stage - Adhere to the principle of looking at points in the reliability of information from diverse sources dispute from others' point of view

- Dispel the blind distrust of information from the government

- Stop viewing conflict resolution - Learn about the shortcoming of the efficiency of as a zero-sum game and seek the dichotomic decisionism, which is likely to induce second best benefit because of the

Final Stage conflicts multiplicity of conflicts

- Stay away from the unilateral resolution of conflicts based on authoritarianism, which ignores general agreement among stakeholders

- Discuss the inevitability of excluding minorities in the process of making decisions on behalf of the majority

- Realize the necessity of education and consulta-

- Cultivate awareness of reasons

Particularities of Online Conflicts ion, given that the direction and content of information may deviate from the government's intention depending on the method used to deliver the information (media=message) for delays in the distribution of public information by the government

- Foster a critical view of the high level of dependence on online communication. 


\section{Guideline for Resolving Conflicts by Conflict Stage}

One of the most important implications of this conflict is that the choice of the communication method has considerable influence on the extent of a conflict between the government and civic groups. In the digital era, people's opinions and expectations about the role of their government are constantly changing, but the attitude and position of the current Korean government seem to be relatively inflexible. In situations in which individuals' thoughts are rapidly changing, the government's slow awareness of the digital generation is likely to result in social conflicts. In this regard, Table 2 provides a guideline on how the government and the public can better resolve conflicts similar to the one considered in this study. For example, in the early stages of a crisis, the government should share relevant information with the public, and the public should understand that delays in the distribution of such information are possible. In the final stages, the government should avoid unilateral resolutions to conflicts based on authoritarianism, and the public should acknowledge the need for sacrifices by certain minorities in the decision-making process. The suggestions, which require no third-party assistance, are provided for each conflict stage.

\section{The Government's Failure and Suggestions}

\section{The Government's Failure}

Lack of a consistent message. The conflict over U.S. beef imports demonstrates that the government was not able to consistently deliver 'value' in the process of approaching the controversial policy. The government failed to create and deliver a unified message to the general public, even though people were sensitive about their food sovereignty, and did not integrate the need for social integration into its message before delivering it.

The period of conflict resolution requires a rational message strategy created in partnership with science and technology professionals and journalists who remain neutral. In fact, an effective prevention method may be based on an integrated information system for conflict coordination at the national level. Such a system can be used to collect related data and develop various alternatives in advance.

Failure to integrate online and offline networks. Openness is one of the main characteristics of any modern digital society. However, the government failed to fully understand the rapidly changing media environment and the openness of the message distribution system. In the digital era, this understanding is critical to persuading and communicating with stakeholders, who are also constantly changing.

Although the conflict had very serious consequences, the government not only did not make full use of conventional media, but also ignored the openness of the Internet and the need for a consistent message. This indicates that the government was negligent in developing diverse alternatives by using both online and offline media.

Failure to build trust in government and positive attitudes toward the government and its policy. The government made a hasty judgment that the conflict would be resolved if it provided the public with some solutions to the U.S. beef import policy. Information receivers tend to change their attitudes readily based on the sincerity and expertise of the information provider. This indicates that, in addition to exercising its power, the government should build trust in government and foster positive attitudes toward the government and its policies, particularly those impacting people's everyday lives (e.g., increases in public utility rates). 
However, in the case of U.S. beef imports, the government did not make serious efforts to provide the public with accurate and trustworthy information, worsening people's attitudes toward the government and its policy. This situation was exacerbated by the government's inability to change people's mind about the policy.

\section{Suggestions}

Establishment of a long-term communication channel. Trade disputes are an integral part of the globalized economy. Therefore, the government should establish a long-term strategy for communication and discard its existing short-sighted attitude (i.e., addressing an issue only when it becomes apparent). A long-term communication channel between the government and the public should have positive effects during periods of conflict formation.

This case demonstrates that mutual distrust tends to expand, not diminish, as a conflict unfolds. In particular, distrust arising from an online conflict tends to be serious, and thus, the government and the public tend to react emotionally, intensifying and prolonging the conflict. Therefore, the government should provide people with more opportunities to participate in the development and implementation of policies, which may positively influence the way in which people frame the government and its policies.

Substantiation of the evaluation and management of conflict stages. The government's attitude toward the public, and not the conflict itself, was the main reason why the conflict led to conflict spillovers. This indicates a need for the government to invest in conflict management programs. Because adhering to a decision may invite and aggravate conflicts, the government should emphasize the process of conflict management.

The case of U.S. beef imports highlights the importance of analyzing the process of conflicts in the digital era and the effects of related opinions through the use of the Internet. Thus, efforts should be made to form expert groups that could evaluate the process of implementing controversial policies in an objective manner.

Experiential communication for controversial policies. Because of the widespread distrust, the government belatedly held a beef-tasting event. Food-related policies are likely to be controversial, and thus, any potential conflicts should be effectively and proactively managed by providing opinion leaders with opportunities to personally experience the potential benefits of such policies; creating favorable attitudes toward policies; and facilitating hands-on PR activities (e.g., TryPR), which have positive word-of-mouth effects.

When people are able to personally experience the benefits of a policy, they are likely to have positive attitudes toward the policy and share their experience with others. Thus, the government should exploit this tendency to foster positive attitudes toward its policies. In particular, the government should make aggressive efforts to assess negative perceptions and constantly evaluate public opinion. 


\section{Notes}

1 "Impeachment of the President Myung-bak Lee, breaking through the 1 million mark of signatures," Segye Daily Newspaper, 4 May 2008, retrieved 11 March 2010, http://net.segye.com/10570.

${ }^{2}$ Krippendorff, K. H., Content analysis: an introduction to its methodology (London: Sage, 1980), Vol 5.

${ }^{3}$ Park, H. W. and Leydesdorff, L., "Understanding the KrKwic: A Computer Program for the Analysis of Korean Text, Focusing on the News about Regional Innovation Posted on Daum.net", Journal of Korean Data Analysis Society 6 (2004): 1377-1388.

${ }^{4}$ Chung, C. J., and Park, H. W., "Textual Analysis of a Political Message: The Inaugural Addresses of Two Korean Presidents," Social Science Information 49 (2010): 215-239.

5 Danowski, J. A., G. A. Barnett and W. Richards (Eds.), "Network analysis of message content," Progress in communication sciences vol.12 (Norwood, NJ: Ablex , 1993): 197-222.

${ }^{6}$ Popping, R., "Knowledge graphs and network text analysis," Social Science Information 42 (2003): 91-106.

${ }^{7}$ Wasserman, S. and Faust, K., Social network analysis: Methods and applications (Cambridge, UK: Cambridge University Press, 1994).

${ }^{8}$ Borgatti, S. P., Everett, M. G., and Freeman, L. C., UCINET for windows: Software for social network analysis (Harvard, MA: Analytic Technologies, 2002).

${ }^{9}$ Park, H. W. and Lee, Y. O., "A Study on reply comments on portal websites by performing the complex text analysis: Kwangwoon University BBK movie clips posted on 'Daum' in the period of the 17th Presidential Election," Journal of the Korean Data Analysis Society, 11 (2009): 731-744.

${ }^{10}$ Doerfel, M. L., and Connaughton, S. L., "Semantic networks and competition: Election year winners and losers in U.S. televised presidential debates, 1960-2004," Journal of the American Society for Information and Science Technology 60 (2009): 201-218.

${ }^{11} \mathrm{McDevitt}, \mathrm{M}$., "Ideological language and the press: Coverage of inaugural, state of the union address," Mass Communications Review 13 (1986): 18-24.

${ }^{12}$ Nimmo, D. and Combs, J. E., Mediated political realities (New York: Longman, 1983).

${ }^{13}$ Riffe, D., Lacy, S., and Fico, F. G., Analyzing media messages, 2nd ed. (Mahwah, NJ: Lawrence Erlbaum Association , 2005).

${ }^{14}$ Lewicki, R., Gray, B., and Eliottm, M., Making sense of intractable environmental conflicts: Concepts and cases (Washington, D.C.: Island Press, 2003).

${ }^{15}$ Jang. E. K. and Koo, K. H., "Candlelight: Violation of the security law in the eyes of prosecutors and the police," Kyunghyang Daily Newspaper, 25 August 2010, Retrieved 11 March 2010 http://news.khan.co.kr/kh_news/khan_art_view.html?artid=201008250249445\&code=9401 00 .

${ }^{16}$ Song, H. K. Where is Korean society going?, Chapter 9. Generation and authority (Seoul, Korea: Good Information, 2005): 285-302.

${ }^{17}$ Cho, D. Y. et al., Where is Korean society going?, Chapter 6. Civil society and authority (Seoul, Korea: Good Information, 2005): 203-238. 